\title{
ABSORBENT PENYARINGAN TERURUT DARI SEMIGRUP IMPLIKATIF
}

\author{
TUTUT IRLA MULTI \\ Program Studi Matematika, \\ Fakultas Matematika dan Ilmu Pengetahuan Alam, Universitas Andalas, \\ Kampus UNAND Limau Manis Padang, Indonesia. \\ im.tutut@yahoo.co.id
}

\begin{abstract}
The simplest algebraic structure is called groupoid, where groupoid is nonempty set with a binary operation. The groupoid which is associative is called a semigroup. A negatively partially ordered semigroup is a set $A$ with a partial ordering and a binary operation. Such $A$ is called implicative if there is an additional binary operation. In this paper will be reviewed the notion of absorbent ordered filters in implicative semigroups. Then it will be studied the relations among ordered filters, absorbent ordered filters, and positive implicative ordered filters.
\end{abstract}

Kata Kunci: Binary operation, implicative semigroup, positive implicative ordered filter, absorbent ordered filter

\section{Pengantar}

Semilattice implikatif merupakan struktur aljabar yang terdiri dari himpunan tak kosong dengan tiga operasi, yaitu operasi terurut parsial, konjungsi, dan implikatif. Lebih jelasnya, semilattice implikatif merupakan suatu sistem $(A, \preceq, \wedge, *)$, di mana $A$ merupakan himpunan tak kosong, $\preceq$ merupakan terurut parsial di $A, \wedge$ merupakan konjungsi dan $*$ merupakan operasi biner di $A$, di mana untuk setiap elemen $x, y, z$ di $A$ berlaku $z \preceq x * y$ jika dan hanya jika $z \wedge x \preceq y$.

Semilattice implikatif secara umum telah dibahas oleh Nemitz [11] dan Blyth [2] yang terkait erat dengan implikasi logika matematika dan teori himpunan beda (Birkhoff [1] dan Curry [5]). Kemudian Nemitz menunjukkan bahwa penyaringan terurut memainkan peranan yang penting dalam perkembangan teori semilattice implikatif. Termotivasi dari hal tersebut, Chan dan Shum [3] menetapkan beberapa sifat dasar dan membentuk struktur penyaringan terurut dari semigrup implikatif.

Kemudian Jun [7] menyelidiki sifat-sifat lain dari semigrup implikatif dan penyaringan terurutnya. Jun, Park, dan William [8] juga mendiskusikan dan mempelajari secara lebih mendalam terkait semigrup implikatif, dengan membangun teori yang lebih lengkap dari penyaringan terurut. Di dalam paper ini, akan dikaji kembali tentang absorbent penyaringan terurut dari semigrup implikatif yang merupakan salah satu jenis subhimpunan dari semigrup implikatif. 


\section{Pendahuluan}

Pada bagian ini akan diuraikan beberapa definisi, teorema dan contoh mengenai semigrup implikatif, semigrup implikatif komutatif, penyaringan terurut, penyaringan terurut implikatif dan penyaringan terurut implikatif positif.

Definisi 2.1. [9] Semigrup terurut parsial secara negatif $(A, \preceq, \bullet)$ adalah suatu himpunan yang terdefinisi terurut parsial " $\preceq "$ dan terdapat suatu operasi biner

" " pada A sedemikian sehingga untuk semua $x, y, z \in A$ berlaku:

(1). $(x \bullet y) \bullet z=x \bullet(y \bullet z)$,

(2). Jika $x \preceq y$ maka $x \bullet z \preceq y \bullet z$ dan $z \bullet x \preceq z \bullet y$,

(3). $x \bullet y \preceq x$ dan $x \bullet y \preceq y$.

Definisi 2.2. [9] Semigrup terurut parsial secara negatif $(A, \preceq, \bullet)$ dikatakan implikatif, jika terdapat operasi biner $*: A \times A \rightarrow A$, sehingga untuk setiap $x, y, z \in A$ berlaku $z \preceq x * y$ jika dan hanya jika $z \bullet x \preceq y$.

Definisi 2.3. [9] Semigrup terurut parsial secara negatif $(A, \preceq, \bullet)$ dikatakan implikatif, jika terdapat operasi biner $*: A \times A \rightarrow A$, sehingga untuk setiap $x, y, z \in A$ berlaku $z \preceq x * y$ jika dan hanya jika $z \bullet x \preceq y$.

Untuk penyederhanaan istilah, semigrup implikatif terurut parsial secara negatif disebut sebagai semigrup implikatif saja.

Contoh 2.4. [9] Misalkan suatu himpunan $T_{1}=\{1, a, b, c, d\}$ yang padanya terdefinisi operasi terurut parsial " berikut:

(1) $d \preceq b \preceq 1$.

(2) $d \preceq c \preceq a \preceq 1$.

(3) $c \preceq a \preceq 1$.

Akan ditunjukkan $T_{1}$ merupakan semigrup implikatif.

Definisi relasi terurut parsial $\preceq$, dapat juga disajikan dengan diagram Hasse sebagaimana yang diperlihatkan pada Gambar 2.4.

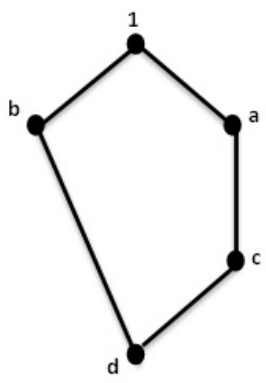

Gambar 1. Diagram Hasse untuk $T_{1}=\{1, a, b, c, d\}$. 
Tabel 1 dan 2 berikut adalah definisi dari operasi " • dan "*" di $T_{1}$.

Tabel 1. Definisi operasi "•" pada $T_{1}=\{1, a, b, c, d\}$.

\begin{tabular}{|l|lllll|}
\hline$\bullet$ & 1 & $a$ & $b$ & $c$ & $d$ \\
\hline 1 & 1 & $a$ & $b$ & $c$ & $d$ \\
$a$ & $a$ & $a$ & $d$ & $c$ & $d$ \\
$b$ & $b$ & $d$ & $b$ & $d$ & $d$ \\
$c$ & $c$ & $c$ & $d$ & $c$ & $d$ \\
$d$ & $d$ & $d$ & $d$ & $d$ & $d$ \\
\hline
\end{tabular}

Tabel 2. Definisi operasi "*" pada $T_{1}=\{1, a, b, c, d\}$.

\begin{tabular}{|l|lllll|}
\hline$*$ & 1 & $a$ & $b$ & $c$ & $d$ \\
\hline 1 & 1 & $a$ & $b$ & $c$ & $d$ \\
$a$ & 1 & 1 & $b$ & $c$ & $d$ \\
$b$ & 1 & $a$ & 1 & $c$ & $c$ \\
$c$ & 1 & 1 & $b$ & 1 & $b$ \\
$d$ & 1 & 1 & 1 & 1 & 1 \\
\hline
\end{tabular}

Berdasarkan Definisi 2.1 - Definisi 2.3, diperoleh $\left(T_{1}, \preceq, \bullet, *\right)$ adalah semigrup implikatif.

Definisi 2.5. [9] Misalkan $(A, \preceq, \bullet, *)$ suatu semigrup implikatif. Maka A dikatakan komutatif jika $x \bullet y=y \bullet x$ untuk semua $x, y \in A$, yaitu $(A, \bullet)$ adalah semigrup komutatif.

Proposisi 2.6. [3] Misalkan A suatu semigrup implikatif maka untuk setiap $x, y, z \in A$, berlaku:

(1). $x \preceq 1$, dimana $x * x=1, x=1 * x$,

(2). $x \preceq y *(x \bullet y)$,

(3). $x \preceq x *(x \bullet x)$,

(4). $x \preceq y * x$,

(5). Jika $x \preceq y$ maka $x * z \succeq y * z$ dan $z * x \preceq z * y$,

(6). $x \preceq y$ jika dan hanya jika $x * y=1$,

(7). $x *(y * z)=(x \bullet y) * z$,

(8). Jika $(A, \bullet)$ merupakan komutatif maka $x * y \preceq(a \bullet x) *(a \bullet y)$ untuk setiap $a \in A$.

Proposisi 2.7. [9] Jika A suatu semigrup implikatif komutatif, maka untuk setiap $x, y, z \in A$, berlaku:

(1). $x *(y * z)=y *(x * z)$, 
(2). $x \preceq(x * y) * y$,

(3). $y * z \preceq(z * x) *(y * x)$,

(4). $y * z \preceq(x * y) *(x * z)$,

(5). $((x * y) * y) * y=x * y$.

Definisi 2.8. [3] Misalkan A suatu semigrup implikatif dan $F$ suatu himpunan bagian tak kosong pada A. Maka $F$ disebut penyaringan terurut dari A jika: (F1). $x \bullet y \in F$ untuk setiap $x, y \in F$. Ini artinya, $F$ suatu subsemigrup dari $A$, (F2). Jika $x \in F$ dan $x \preceq y$, maka $y \in F$.

Proposisi 2.9. [10] Misalkan A suatu semigrup implikatif dan F suatu himpunan bagian tak kosong pada A. Maka F merupakan penyaringan terurut pada A jika dan hanya jika berlaku:

(F3). $1 \in F$,

(F4). Jika $x * y \in F$ dan $x \in F$, maka $y \in F$ untuk setiap $y \in A$.

Lema 2.10. [6] Misalkan A semigrup implikatif dan $F$ suatu himpunan bagian tak kosong pada A. Himpunan $F$ merupakan penyaringan terurut pada A jika dan hanya jika berlaku:

(F5). Jika $x \preceq y * z$, maka $z \in F$ untuk setiap $x, y \in F$ dan $z \in A$.

Definisi 2.11. [6] Misalkan A semigrup implikatif dan $F$ suatu himpunan bagian tak kosong pada A. F dikatakan penyaringan terurut implikatif dari A jika memenuhi:

(F3). $1 \in F$,

(F6). Jika $x *(y * z) \in F$ dan $x * y \in F$, maka $x * z \in F$ untuk setiap $x, y, z \in A$.

Lema 2.12. [6] Misalkan A semigrup implikatif. Jika F penyaringan terurut implikatif dari $A$, maka berlaku:

(F7). Jika $x *(x * y) \in F$, maka $x * y \in F$ untuk setiap $x, y \in A$.

Lema 2.13. [6] Misalkan A semigrup implikatif. Maka setiap penyaringan terurut implikatif dari A adalah penyaringan terurut dari $A$.

Definisi 2.14. [4] Misalkan A semigrup implikatif dan $F$ yang merupakan suatu himpunan bagian tak kosong pada A.F dikatakan penyaringan terurut implikatif positif dari A jika memenuhi:

(F3). $1 \in F$,

(F8). Jika $x *((y * z) * y) \in F$ dan $x \in F$ maka $y \in F$ untuk setiap $x, y, z \in A$.

Teorema 2.15. [4] Misalkan A semigrup implikatif. Maka setiap penyaringan terurut implikatif positif dari $A$ adalah penyaringan terurut dari $A$.

Teorema 2.16. [4] Misalkan A semigrup implikatif dan $F$ penyaringan terurut pada A. F adalah penyaringan terurut implikatif positif dari A jika dan hanya jika berlaku:

(F9). Jika $(x * y) * x \in F$ maka $x \in F$ untuk setiap $x, y \in A$. 


\section{Absorbent Penyaringan Terurut}

Pada bagian ini akan diuraikan beberapa definisi dan teorema terkait absorbent penyaringan terurut.

Definisi 3.1. [8] Misalkan A suatu semigrup implikatif dan F suatu himpunan bagian tak kosong pada A. Maka $F$ dikatakan suatu absorbent penyaringan terurut dari A jika memenuhi:

(F3). $1 \in F$,

(F10). Jika $z *(y * x) \in F, z \in F$, maka $((x * y) * y) * x \in F$, untuk setiap $x, y \in A$.

Teorema 3.2. [8] Misalkan A merupakan semigrup implikatif. Maka setiap absorbent penyaringan terurut $F$ dari $A$ adalah penyaringan terurut dari $A$.

Bukti. Asumsikan bahwa $F$ merupakan absorbent penyaringan terurut dari $A$. Akan ditunjukkan $F$ penyaringan terurut dari $A$. Misalkan $x, y, z \in A$. Misalkan $z * x \in F$ dan $z \in F$. Akan ditunjukkan $x \in F$. Perhatikan bahwa $z * x=z *(1 *$ $x$ ) (Proposisi $2.5(1)$ ). Sehingga diperoleh $z *(1 * x) \in F$ dan $z \in F$ (karena $F$ absorbent). Maka,

$$
\begin{aligned}
((x * 1) * 1) * x & =(1 * 1) * x, \quad(\text { Proposisi } 2.5(6)) \\
& =1 * x(\text { Proposisi } 2.5(1)) \\
& =x \in F
\end{aligned}
$$

Oleh karena itu, $F$ penyaringan terurut dari $A$.

Teorema 3.3. [8] isalkan A merupakan semigrup implikatif. Maka suatu penyaringan terurut $F$ dari $A$ adalah absorbent penyaringan terurut dari $A$ jika dan hanya jika berlaku:

(F11). $y * x \in F$, maka $((x * y) * y) * x \in F$ untuk setiap $x, y \in A$.

Bukti. $(\Rightarrow)$ Asumsikan bahwa $F$ absorbent penyaringan terurut dari $A$. Akan ditunjukkan bahwa jika $y * x \in F$, maka $((x * y) * y) * x \in F$ untuk setiap $x, y \in A$. Ambil $x, y, z \in A$ dan misalkan $(y * x) \in F$. Perhatikan bahwa

$$
(y * x)=1 *(y * x) \in F(\text { Proposisi } 2.5(1)) .
$$

Karena $F$ penyaringan terurut maka $1 \in F(\mathrm{~F} 3)$. Karena $1 *(y * x) \in F$, dan $1 \in F$ serta diketahui bahwa $F$ absorbent, maka berdasarkan Definisi 3.1 (untuk $z=1$ ) maka diperoleh

$$
((x * y) * y) * x \in F(F 10) .
$$

$(\Leftarrow)$ Asumsikan bahwa $F$ penyaringan terurut dari $A$ yang memenuhi (F11). Akan ditunjukkan $F$ absorbent penyaringan terurut dari $A$. Karena $F$ penyaringan terurut maka $1 \in F(\mathrm{~F} 3)$. Misalkan $x, y, z \in A$ sedemikian sehingga $z *(y * x) \in F$ dan $z \in F$, maka $y * x \in F(\mathrm{~F} 4)$. Oleh karena itu $((x * y) * y) * x \in F(\mathrm{~F} 11)$.

Dengan demikian dapat disimpulkan bahwa $F$ absorbent penyaringan terurut dari $A$. 
Teorema 3.4. [8] Misalkan A merupakan semigrup implikatif komutatif. Maka setiap penyaringan terurut implikatif positif $F$ dari $A$ adalah absorbent penyaringan terurut dari $A$.

Bukti. Asumsikan bahwa $F$ merupakan penyaringan terurut implikatif positif dari $A$. Akan ditunjukkan $F$ absorbent penyaringan terurut dari $A$. Karena $F$ penyaringan terurut implikatif positif dari $A$, maka $F$ merupakan penyaringan terurut dari $A$ (Teorema 2.16). Untuk membuktikan teorema ini, akan digunakan Teorema 3.3 .

Misalkan $x, y \in A$. Misalkan $y * x \in F$. Akan ditunjukkan $((x * y) * y) * x \in F$. Perhatikan bahwa:

$$
x \preceq((x * y) * y) * x, \quad(\text { Proposisi } 2.5(4)) .
$$

Akibatnya $(((x * y) * y) * x) * y \preceq x * y$ (Proposisi $2.5(5))$.

Asumsikan $a=((x * y) * y) * x$.

Diperoleh

$$
\begin{aligned}
(a * y) * a & =(((x * y) * y) * x) * y) *(((x * y) * y) * x) \\
\succeq & (x * y) *(((x * y) * y) * x)(\text { Proposisi } 2.5(5)) \\
& =((x * y) * y) *((x * y) * x)(\text { Proposisi } 2.6(1)) \\
& \succeq y * x(\text { Proposisi } 2.6(4)) .
\end{aligned}
$$

Karena $y * x \in F$ dan $y * x \preceq(a * y) * a$ maka $(a * y) * a \in F(\mathrm{~F} 2)$.

Karena $(a * y) * a \in F$ maka $a \in F$ (F9). Sehingga dapat disimpulkan bahwa $F$ absorbent penyaringan terurut dari $A$.

Teorema 3.5. [8] (Perluasan Sifat) Misalkan A merupakan semigrup implikatif komutatif dan misalkan $F$ dan $G$ merupakan penyaringan terurut dari $A$, sedemikian sehingga $F \subseteq G$. Jika $F$ absorbent penyaringan terurut dari $A$ maka $G$ absorbent penyaringan terurut dari $A$.

Bukti. Asumsikan bahwa $F$ merupakan absorbent penyaringan terurut dari $A$. Akan ditunjukkan $G$ absorbent penyaringan terurut dari $A$, di mana $F \subseteq G$. Untuk membuktikan teorema ini, akan digunakan Teorema 3.3.

Misalkan $x, y \in A$ dan $y * x \in G$. Akan ditunjukkan $((x * y) * y) * x \in G$. Perhatikan bahwa:

$$
\begin{aligned}
y *((y * x) * x) & =(y * x) *(y * x)(\text { Proposisi } 2.6(1)), \\
& =1 \in F(\text { Proposisi } 2.5(1)) .
\end{aligned}
$$

Karena $F$ absorbent maka berlaku:

$$
((((y * x) * x) * y) * y) *((y * x) * x) \in F, \text { (Teorema 3.3). }
$$

Sehingga

$$
(y * x) *(((((y * x) * x) * y) * y) * x) \in F \subseteq G \text { (Proposisi } 2.6(1)) .
$$


Karena $y * x \in G$ maka $((((y * x) * x) * y) * y) * x \in G(\mathrm{~F} 4)$. Kemudian perhatikan bahwa

$$
\begin{aligned}
& (((((y * x) * x) * y) * y) * x) *(((x * y) * y) * x), \\
\succeq & ((x * y) * y) *((((y * x) * x) * y) * y), \quad(\text { Proposisi } 2.6(3)), \\
\succeq & (((y * x) * x) * y) *(x * y),(\text { Proposisi } 2.6(3)), \\
\succeq & x *((y * x) * x), \quad(\text { Proposisi } 2.6(3)), \\
= & (y * x) *(x * x),(\text { Proposisi } 2.6(1)), \\
= & (y * x) * 1,(\text { Proposisi } 2.5(1)), \\
= & 1 \in G .
\end{aligned}
$$

Berdasarkan (F5) diperoleh $((x * y) * y) * x \in G$. Akibatnya $G$ absorbent penyaringan terurut dari $A$.

\section{Kesimpulan}

Misalkan $A$ adalah suatu semigrup implikatif, $F$ himpunan tak kosong dan merupakan penyaringan terurut pada $A$. Maka syarat perlu dan syarat cukup $F$ merupakan absorbent penyaringan terurut dari $A$ adalah:

Jika $(y * x) \in F$ maka $((x * y) * y) * x \in F$ untuk setiap $x, y \in A$.

Misalkan $A$ adalah suatu semigrup implikatif komutatif, $F$ dan $G$ penyaringan terurut pada $A$, di mana $F \subseteq G$. Jika $F$ absorbent penyaringan terurut pada $A$, maka $G$ juga absorbent penyaringan terurut pada $A$.

\section{Ucapan Terima Kasih}

Penulis mengucapkan terima kasih kepada Bapak Dr. Admi Nazra, Ibu Dr. Yanita, Bapak Prof. I Made Arnawa serta Ibu Nova Noliza Bakar, M.Si yang telah memberikan masukan dan saran sehingga makalah ini dapat diselesaikan dengan baik.

\section{Daftar Pustaka}

[1] Birkhoff, G. 1967. Lattice Theory. American Mathematical Society, Amerika. Vol. XXV

[2] Blyth, T. S. 1965. Pseudo-residual in Semigroups. London Mathematical Society, Inggris. 40: $441-454$

[3] Chan, M. W. dan K. P. Shum. 1993. Homomorphism of Implicative Semigroups. Semigroup Forum. 46(1): 7 - 15

[4] Connell, E. H. 2002. Elements of Abstract and Linear Algebra. Department of Mathematicc. University of Miami, USA

[5] Curry, H. B. 1963. Foundation of Mathematics Logic. McGrow-Hill, New York

[6] Jun, Y. B. 1999. Implicative Ordered Filters of Implicative Semigroups. Korean Mathematical Society, Korea. 14(1): $47-55$

[7] Jun, Y. B. 2007. Folding Theory Applied to Implicative Ordered Filters of Implicative Semigroups. Asia Tenggara. 31: 893 - 901 
92 Tutut Irla Multi

[8] Jun, Y. B., C. H. Park dan D. R. P. Williams. 2009. Absorbent Ordered Filters and Their Fuzzications in Implicative Semigroups. Iranian Journal of Fuzzy Systems. 6(1): $45-61$

[9] Jun, Y. B. dan K. H. Kim. 2000. Positive Implicative Ordered Filters of Implicative Semigroups. Internat. J. Math. dan Math. Sci. 23(12): $801-806$

[10] Jun, Y. B., J. Meng dan X. L. Xin. 2000. On Ordered Filters of Implicative Semigroups. Semigroup Forum. 54: $75-82$

[11] Nemitz, W. C. 1995. Implicative Semi-lattice. American Mathematical Society, Amerika. 117: 128 - 142

[12] Susanti, Elva. 2013. Karakterisasi Himpunan Bagian dari Semigrup Implikatif Ideal. Tesis-S2, tidak dipublikasikan. Universitas Andalas, Padang 